\title{
Há insetos por todos os lados: um relato de experiência na Educação Infantil
}

\begin{abstract}
Resumo:
Tendo as crianças como protagonistas dos processos de ensino e aprendizagem, este artigo apresenta uma reflexão acerca do trabalho com o tema de pesquisa "insetos", em uma turma da Educação Infantil do Núcleo de Educação da Infância - NEI - CAp/UFRN, Colégio de Aplicação vinculado à Universidade Federal do Rio Grande do Norte. O tema de pesquisa é a metodologia de trabalho utilizada desde a sua reestruração curricular na década de 1980, busca articular os conhecimentos dos diversos campos de experiências, o contexto sociocultural das crianças, seus interesses e suas curiosidades para compreender o objeto de estudo (PERNAMBUCO, 1994; RÊGO, 1999). No relato descrevemos algumas situações que possibilitaram o desenvolvimento de uma ação significativa com as crianças, favorecendo vivências baseadas na dialética do conhecimento. Por fim, evidenciamos os avanços significativos na ampliação dos saberes, das expressões e das linguagens das crianças.
\end{abstract}

\section{Palavras-chave:}

Educação Infantil. Tema de pesquisa. Relato de experiência.

\begin{abstract}
:
Having children as protagonists of the teaching and learning processes, this article presents a reflection on the work with the research theme "insects", in a group of Early Childhood Education at the Childhood Education Center - NEI - CAp/UFRN, Application College linked to the Federal University of Rio Grande do Norte. The research theme, work methodology used since its curricular restructuring in the 1980s, articulates the knowledge of the different fields of experience, the sociocultural context of the children, their interests and their curiosities to understand the object of study (PERNAMBUCO, 1994; RÊGO, 1999). In the report we describe some situations that made it possible to develop a meaningful action with children, favoring experiences based on the dialectic of knowledge. Finally, we highlight the significant advances in the expansion of children's knowledge, expressions and languages.
\end{abstract}

\section{Keywords:}

Kindergarten. Research theme. Experience report.

\footnotetext{
* Mestre em Educação. Professora de Ensino Básico Técnico e Tecnológico no Núcleo de Educação da Infância, Colégio de Aplicação da Universidade Federal do Rio Grande do Norte. E-mail: esthephania@nei.ufrn.br. ORCID iD: http://orcid.org/00000002-4648-7817.

** Mestranda no Programa de Pós-graduação em Inovações em Tecnologias Educacionais Professora de Ensino Básico Técnico e Tecnológico no Núcleo de Educação da Infância, Colégio de Aplicação da Universidade Federal do Rio Grande do Norte. E-mail: neidinha@nei.ufrn.br. ORCID iD: http://orcid.og/0000-0001-5344-2687.
} 


\section{Introdução}

As crianças aprendem por imitação, brincadeira, pela interação com o ambiente, com outras crianças e com os adultos. Nesse sentido, são instigadas pelas relações sociais, pela curiosidade e interesse pelos fenômenos naturais, pelo enfrentamento das situações que vivenciam em suas interações com os outros e com os objetos presentes no mundo em que vivem e, assim, aprendem de diferentes jeitos, em variados contextos e pela interação com sujeitos diversos.

Nesse contexto, a escola de Educação Infantil é um espaço de aprendizagem e produção de cultura e as crianças são sujeitos do conhecimento, da sua aprendizagem e produzem conhecimentos na interação com os outros, e com os objetos de conhecimento.

Desse modo, este relato de experiência se constitui em um recorte da prática pedagógica realizada com uma turma da Educação Infantil do Núcleo de Educação da Infância - NEI, Colégio de Aplicação da Universidade Federal do Rio Grande do Norte, durante o primeiro trimestre do ano de 2018. A turma era composta por 22 crianças na faixa etária entre quatro e cinco anos de idade, além de duas professoras e uma auxiliar de creche.

Neste relato abordaremos o trabalho pedagógico desenvolvido a partir do tema de pesquisa "insetos". Descrevemos as primeiras falas, sentimentos, ideias e descobertas expressadas/vivenciadas no início dessa trajetória, bem como as principais atividades e conquistas decorrentes desse momento tão significativo na vida das crianças.

Assim, tem como objetivo refletir sobre as vivências/intervenções pedagógicas que privilegiaram o tema de pesquisa, metodologia de trabalho do NEI - CAp/UFRN. Buscando articular os conhecimentos dos diversos campos de experiências, o contexto sociocultural das crianças ou suas realidades imediatas, seus interesses e suas curiosidades para compreender o objeto de estudo.

Durante esta prática, criamos situações que possibilitaram o desenvolvimento de uma ação significativa com as crianças, considerando a pesquisa como o fio condutor de saberes e fazeres.

Entendemos, assim como nos apontam Delizoicov, Angotti e Pernambuco (2002), que o indivíduo está constantemente elaborando significações sobre o mundo natural e social no qual está inserido. Explicações que vão sendo constituídas desde muito cedo em conjunto com a linguagem e que vão permanecendo ou se modificando ao longo da vida, conforme as suas experiências. Nesse aspecto, a escola se constitui como um dos espaços, mas não exclusivo, em que os conhecimentos e explicações sobre esses fenômenos naturais e sociais podem ser construídos.

\section{A metodologia do tema de pesquisa: alguns apontamentos}

Na metodologia do tema de pesquisa, o ponto de partida são as ideias das crianças sobre o que irá ser estudado, para só então e a partir delas, selecionar os objetivos e experiências que auxiliarão na ampliação desses conhecimentos prévios e das questões do grupo. Segundo Rêgo (1999, p. 62) o tema de pesquisa é “[...] uma forma de considerar as experiências de vida e valores socioculturais das crianças, garantindo o acesso às experiências, onde possam expressar, ampliar e atualizar suas ideias, conhecimentos e sentimentos". Desse modo, ao organizar e sistematizar as ações desenvolvidas nos estudos sobre o tema de pesquisa "insetos", consideramos os interesses, curiosidades e questionamentos do grupo.

Nesse movimento, professores e crianças apropriam-se dos conhecimentos dos diferentes campos de experiências e saberes na medida em que vão buscar respostas para suas questões. Assim, o tema de pesquisa não se constitui só num aglutinador de conhecimentos sobre o assunto, mas, acima de tudo, em um provocador de construção/ampliação/resgate de conhecimentos significativos (RÊGO, 1999).

Em nossa instituição, o trabalho com o tema de pesquisa se organiza a partir de três momentos pedagógicos: Estudo da Realidade - ER (momento em que se faz o levantamento prévio do que as crianças já sabem sobre o tema e o que querem saber); Organização do Conhecimento - OC (momento em que 
são realizados estudos e ações que levem à exploração das questões de pesquisa) e Aplicação do Conhecimento - AC (momento em que os saberes são sistematizados para socialização entre as próprias crianças, pais ou comunidade escolar). Segundo Rêgo (1999), esses momentos não se constituem em fases estanques por considerarem as curiosidades e necessidades das crianças, permitindo novos desdobramentos para os estudos, conforme elas vão apresentando novas demandas.

Esse modo de ver a criança envolve compreendê-la como sujeito e não como objeto de pesquisa e isso implica em pensar sobre quem são essas crianças, em que contextos vivem, com quem convivem, que experiências estão tendo, o que lhes desperta curiosidade (DELGADO; MULLER, 2005), para só assim reconhecê-las como foco da aprendizagem.

Nesse processo, nós, professoras, como organizadoras do trabalho, observávamos, ouvíamos e questionávamos as crianças, buscando identificar, na fala delas, o que já sabiam e o que gostariam de saber a respeito do assunto a ser estudado - os insetos. Nesse momento, entendemos que é papel do professor desenvolver uma "escuta atenta", perceber o que as crianças já conhecem; o que já construíram acerca daquele assunto.

\section{Recorte de uma prática pedagógica sobre a vida dos insetos: pesquisar, observar, brincar e registrar}

Desse modo, o tema de pesquisa "insetos" surge da observação dos interesses das crianças desde os primeiros dias no NEI já que, com frequência, percebíamos as crianças contando suas vivências com borboletas, formigas, abelhas e outros insetos.

Além disso, no momento do parque, observávamos com frequência as crianças manipulando, com muita curiosidade, pequenos animais como: besouros, formigas, baratas e embuás. E, quase que diariamente, as crianças nos procuravam para mostrar as suas descobertas, mencionando: "Olha professora, encontrei uma formiga", "Essa formiga pica?", "Professora, eu vi uma borboleta na minha casa e ela saiu do casulo". Assim, as falas e ações das crianças foram nos apontando caminhos para a escolha do nosso primeiro tema de pesquisa daquele ano.

Contribuiu, ainda, para a escolha do tema de pesquisa "insetos", a nossa observação de alguns momentos em que as crianças apontavam animais como aranha, passarinho, escorpião e lagartixa como pertencentes à classe dos insetos, como ocorreu em um dia durante a roda de conversas, no qual duas crianças passaram a discutir se aranha era ou não um inseto. Na ocasião, uma delas afirmava que aranha não era inseto, mas sim um aracnídeo e a outra, muito inconformada, dizia que a aranha era sim um inseto e que era um inseto que comia outros insetos.

Em outra ocasião, outra criança levou uma lagartixa para sala e chegou afirmando que havia pego um inseto em sua casa, enquanto as outras crianças não concordavam e diziam que para ser inseto tinha que ter antenas e que aranha não tinha antenas, por isso não era possível que ela fosse da classe dos insetos.

Desse modo, passamos a observar que aquele assunto mobilizou o grupo gerando inquietações e questionamentos e que, além da necessidade de um diálogo e aprofundamento das questões que surgiram, o tema "insetos" poderia também aglutinar conceitos de outras áreas do conhecimento, assim como nos aponta Rêgo (1999) com relação aos critérios para que um assunto possa se tornar um tema de pesquisa.

No NEI/CAp - UFRN nossas práticas/ações partem da perspectiva de que na Educação Infantil deve-se garantir experiências que "incentivem a curiosidade, a exploração, o encantamento, o questionamento, a indagação e o conhecimento das crianças em relação ao mundo físico e social, ao tempo e à natureza", como é afirmado no texto das Diretrizes Curriculares Nacionais para Educação Infantil - DCNEI (BRASIL, 20010, p. 26).

A esse respeito, a Base Nacional Comum Curricular (BRASIL, 2017, p. 41) também aponta a relevância desta etapa da educação em possibilitar às crianças experiências em que possam "[...] manipular objetos, investigar e explorar seu entorno, levantar hipóteses e consultar fontes de informação para buscar respostas às suas curiosidades e indagações". 
Partindo dessa perspectiva percebíamos que o grupo era movido por uma curiosidade e pelo desejo de conhecer mais sobre esses pequenos animais e que este poderia ser o fio condutor do nosso estudo. Além disso, observávamos que uma questão perpassava a maior parte das conversas das crianças sobre os insetos: o que diferenciava os insetos de outras classes de animais? O que caracterizava os insetos?

Assim, considerando a curiosidade e o entusiasmo do grupo com relação a esses pequenos animais, durante a roda inicial levamos, para compartilhar com as crianças, imagens impressas dos animais (formiga, borboleta, mosquito, lagartixa, passarinho) que eram citados em suas conversas e pedimos para que elas apontassem o que havia de comum e de diferente entre eles.

Nesse diálogo, as crianças foram instigadas a pensar e elaborar conhecimentos sobre os insetos. $\mathrm{O}$ nosso objetivo era fazer com que elas percebessem as semelhanças e diferenças entre esses animais. Assim, uma criança foi logo dizendo que alguns deles eram parecidos "porque voavam" e outra discordou dizendo "o passarinho tem asas, ele voa, mas ele não é da família dos insetos, ele é da família das aves". Nesse movimento, outras crianças foram apontando semelhanças entre alguns dos animais: "olha, eles (abelhas, borboletas, mosquitos) têm antenas". Outra criança falou: "os bichos parecidos são borboletas, abelhas e moscas porque voam". Uma delas falou empolgada: "eles têm ferrão!" (apontando para as imagens da abelha e da formiga).

Nessa ocasião, as crianças também continuaram falando sobre suas vivências, dizendo que já haviam visto esses animais no jardim de casa, no parque do NEI, no lixo, no banheiro e em diferentes espaços.

Então, em um outro momento, ao compartilharmos com as crianças novamente algumas imagens - só que dessa vez somente de alguns insetos -, passamos a chamar a atenção para algumas das suas características como antenas e quantidade de pernas. Assim, ao mesmo tempo em que olhavam as imagens, fomos questionando: "quais destes bichos têm antenas? Quantas pernas eles têm?". Com isso, as crianças passaram a dizer quais daqueles animais tinham antenas e a perceber que alguns daqueles animais tinham seis pernas atentando para algumas características em comum dos insetos.

Após essa vivência, falamos para as crianças que aqueles animais que elas haviam agrupado, por perceberem semelhanças entre eles, na verdade, pertenciam a uma mesma classe, a dos insetos e que era como se eles pertencessem a uma grande família.

Assim, definimos algumas ações para desencadearmos ainda mais o interesse e a curiosidade em relação aos insetos. Segundo Rêgo (1999), para que um assunto se torne um tema de estudo, de pesquisa, precisa tornar-se, antes, um tema de interesse, de curiosidades e necessidade por parte das crianças e envolvimento de todo grupo. Mas o que as crianças já conheciam e o que precisavam conhecer sobre os insetos?

A partir do levantamento desses questionamentos e indagações das crianças, foi possível traçar os nossos objetivos de aprendizagem: i) Conhecer algumas características dos insetos; ii) Conhecer algumas diferenças entre os insetos e outros animais (lagartixa e aranha); iii) Reconhecer os insetos mais comuns no nosso cotidiano; iv) Conhecer o habitat de alguns insetos; vi) Conhecer a alimentação de alguns insetos; vii) Conhecer mecanismos de defesa de alguns insetos; viii) Desenvolver atitudes de cuidados com o nosso corpo em relação aos insetos; ix) Conhecer os modos de organização dos insetos sociais (abelhas e formigas).

Durante o estudo do tema de pesquisa, é prática em nossa instituição enviarmos para as famílias um bilhete contextualizando o tema a ser estudado, como também solicitando que nos enviem materiais que possam contribuir com o estudo da nossa temática. Desse modo, pedimos que as crianças pesquisassem em casa com a ajuda da família e nos enviassem materiais como imagens, textos informativos, vídeos e/ou outras informações que pudessem enriquecer nossa investigação sobre os insetos.

Assim, nos dias que se seguiram foram chegando muitas novidades sobre o tema como imagens da internet, fotos, informações e vídeos, além de livros informativos e de literatura sobre os insetos. Recebemos, ainda, muitos insetos e outros animais, vivos e mortos, trazidos pelas famílias, como formigas, besouros, soldadinhos, grilos, borboletas, mariposas, libélulas, além de uma lagarta na qual pudemos alimentá-la com folhas e observá-la desde a sua fase larval até a transformação em pupa. É importante apontar que o contato das crianças com estes pequenos seres possibilitou que elas observassem, estabelecessem comparações e avançassem em suas hipóteses iniciais. 
Deheinzelin (1994) nos diz que a ciência não é, portanto, uma coleção de verdades que explicam o real. Ela é constituída de imagens, de referências teóricas que se valem de linguagens, desta forma, transformamos a realidade ao mesmo tempo em que nos transformamos, na tentativa de dar sentido ao mundo. Desse modo, consideramos como imprescindíveis esses momentos de contato com insetos e outros animais, resultando numa relação investigativa que faz com que as crianças olhem com curiosidade questionadora diante destes pequenos animais.

Também nessa perspectiva Arce, Silva e Varotto (2011, p. 61) apontam a ciência como “[...] fruto da criação humana, da utilização de seus processos de imaginação". Nesse aspecto, tais autores afirmam ainda que as crianças ao vivenciarem e elaborarem as experiências - nesse mundo real no qual fazem parte entendem melhor as ações humanas e os conhecimentos que delas foram advindos e acumulados ao longo da história da humanidade. Desse modo, compreendemos que as vivências possibilitadas às crianças neste período do desenvolvimento devem estar conectadas à realidade já que, em grande medida, os conhecimentos científicos foram/são frutos da criação e imaginação dos sujeitos em seus contextos de vida.

Os campos de experiências citados pela BNCC propõem que acolhemos as experiências e os saberes das crianças, promovendo situações que elas interajam mais entre si, discutam as regras, ampliem os conhecimentos, a imaginação, a criatividade, as experiências emocionais, expressivas, cognitivas, sociais e relacionais (BRASIL, 2017). Assim, colocam no foco do processo educacional as interações e as brincadeiras, de onde surgem as observações, as indagações, as investigações e as outras ações das crianças, articuladas com as experiências propostas pelas professoras.

Desse modo, as aprendizagens com o tema de pesquisa "insetos" foram permeadas pela observação, pesquisa e interação com esses pequenos animais e, nesse processo, recebemos muitos insetos em nossa sala, fossem trazidos por um familiar, por funcionários da nossa escola, por nós professores ou pelas próprias crianças que, cotidianamente, nos convidavam a "coletar" insetos para o nosso estudo. Na maioria das vezes, eram insetos que estavam sem vida no parque como formigas ou borboletas, por exemplo. Nossas práticas partiam do entendimento de que, conforme nos esclarece Tiriba (2006, p. 8), "viver é conhecer, conhecer é viver, num movimento que pressupõe um estado de interação entre seres vivos e meio".

Assim, após a escolha do tema, planejamos atividades prazerosas e significativas para as crianças que possibilitassem a vivência de experiências que resultassem em aprendizagens, a partir de uma ação intencional e mediada por nós professores, os outros mais experientes nesse processo. Nessa perspectiva, nosso papel é o de organizadoras do trabalho, em consonância como o que discorre Freire (2007, p. 21): "Organizador no sentido, porém, de quem observa, colhe os dados, trabalha em cima deles, com total respeito aos educandos que não podem ser puros objetos da ação do professor”.

A seguir, descreveremos, em um pequeno recorte, as atividades mais significativas, desenvolvidas junto a esse grupo com o tema de pesquisa "insetos".

O primeiro passo foi solicitar que as crianças registrassem por meio do desenho suas ideias iniciais sobre os insetos, momento descrito por Rêgo (1999), durante trabalho com o tema de pesquisa, como parte do Estudo da Realidade - ER. Partimos do entendimento de que os desenhos das crianças poderiam nos dar algumas pistas de como elas estavam pensando a temática a ser estudada ou nos mostrar aspectos que, de algum modo, poderiam não terem sido percebidos em suas falas.

Esses desenhos também foram importantes para que, ao final da pesquisa, pudéssemos perceber avanços nos modos de representar das crianças. Entretanto, é importante ressaltar que essas representações das crianças narram suas experiências de acordo com o ponto de vista de cada uma delas sobre a realidade. Conforme nos mostram Cunha et al. (2017, p. 44), "essas representações não têm o compromisso de ser realistas, no sentido de representar as coisas tal qual nós a vemos".

Após esta exploração inicial, mediamos os momentos de Organização do Conhecimento - OC (RÊGO, 1999), no qual planejamos atividades que possibilitaram a apropriação do saber através dos Campos de Experiência.

Nesse contexto, em um primeiro momento, abordamos as características físicas desses pequenos animais, a partir da observação e manipulação dos insetos, leituras de imagens, vídeos, construção de 
quebra-cabeça, representações por desenhos e modelagens, dentre outras experiências que nos possibilitaram o conhecimento da estrutura corpórea desses animais que, ao mesmo tempo em que são diversos entre si, carregam semelhanças que os aproximam enquanto grupo.

Em um segundo momento, nos detivemos ao conhecimento das diferenças entre os insetos e outros animais. Para isso, recorremos a algumas estratégias metodológicas como apreciação de slides, vídeos e imagens, produção de registros escritos e atividades de classificação (coletivas e individuais), nas quais era possível agrupar insetos e outros animais, segundo suas semelhanças e diferenças.

Para construirmos conhecimentos sobre o habitat dos insetos, trabalhamos com leituras de imagens de formigueiro, colmeia, floresta e lixão. Assim, pudemos aprender sobre a moradia de insetos como formiga, abelha, borboletas, moscas e baratas. Além disso, pudemos representar o habitat das formigas e, utilizando argila, construir muitos formigueiros. Ainda com o objetivo de trabalhar este habitat e de perceber que os insetos estão em muitos lugares, fizemos uma visita a um dos jardins do NEI e, a partir da leitura de imagens de fotos que fizemos desse lugar, nos inspiramos e produzimos lindas pinturas, utilizando a técnica da pintura, do desenho e da colagem.

Construímos, ainda, conhecimentos sobre os mecanismos de defesa dos insetos e descobrimos, com o auxílio da nossa caixa de curiosidades, composta por muitas informações sobre insetos, que alguns deles picam para se defender, como abelhas, vespas e maribondos e outros mordem para se alimentar como mosquitos, cupins e pulgas.

Além disso, aprendemos com o auxiliar da turma que é graduado em Enfermagem, como podemos fazer para cuidar do nosso corpo, caso sejamos picados ou mordidos por algum inseto. Todas essas informações foram sistematizadas em um texto coletivo que foi exposto em um mural da nossa sala para que as crianças da Turma 3 da tarde também aprendessem a cuidar das mordidas e/ou picadas dos insetos.

Aprendemos, ainda, em vídeos e slides que os insetos comem de tudo, considerando que eles são o maior grupo de animais existentes em nosso planeta. Desse modo, a alimentação dos insetos é bem variada, já que pode ser composta por plantas ou animais em decomposição.

Como síntese desses momentos vivenciados, fizemos alguns textos coletivos. Esse é um dos momentos em que as crianças podem acionar o que aprenderam, sobre o tema configurando-se na perspectiva da nossa metodologia como Aplicação do Conhecimento - AC (RÊGO, 1999). Mas, antes da produção propriamente dita, voltamos às questões iniciais e, aos poucos, fomos levantando os pontos mais significativos e organizando a fala das crianças para a produção do que tínhamos aprendido sobre os insetos.

Na produção do texto coletivo, uma das professoras atuou como escriba enquanto as crianças foram relatando o que gostariam que fosse escrito no texto. Assim, nesse movimento de organização do pensamento, as crianças foram retomando o percurso do seu aprendizado.

\section{Considerações finais}

Por fim, ao final deste estudo, podemos dizer que foi muito significativo e enriquecedor o estudo do tema de pesquisa "insetos", tendo em vista que a temática surgiu do interesse do grupo, permitindo a ampliação dos conhecimentos de forma lúdica e prazerosa.

Ao refletirmos sobre essa experiência, reiteramos as considerações de Deheinzelin (1994) ao afirmar que a ciência não é um conjunto de verdades que explicam o real, mas é constituída nesse movimento de dar sentido ao mundo e a realidade por meio de imagens, referências e linguagens.

Nesse sentido, ressaltamos a importância de garantir experiências que possibilitem a curiosidade, 0 encantamento e a indagação em relação ao mundo natural conforme nos apontam os documentos oficiais das Diretrizes Curriculares Nacionais para a Educação Infantil (BRASIL, 2010) e da Base Nacional para a Educação Infantil (BRASIL, 2017).

Ao encerrarmos o estudo, pudemos refletir sobre as aprendizagens das crianças e nossa prática pedagógica, retomando os objetivos traçados. Com o desenvolvimento deste tema exploramos as primeiras 
falas, sentimentos, ideias e descobertas expressados/vivenciados no início dessa trajetória, bem como as principais vivências e conquistas decorrentes desse momento tão significativo na vida das crianças.

Reiteramos a importância da curiosidade questionadora das crianças diante dos fenômenos da natureza e do nosso papel enquanto mediadores dessa reação investigativa que desde cedo estabelecem em suas tentativas de darem sentido ao mundo.

Consideramos assim, que este relato poderá contribuir para uma reflexão crítica acerca das propostas e práticas pedagógicas na Educação Infantil, envolvendo o uso de várias linguagens para que possam ser ampliadas as possibilidades concretas das crianças se tornarem protagonistas do processo educativo.

\section{Referências}

ARCE, Alessandra; SILVA, Debora; VAROTTO, Michele. Ensinando ciências na Educação Infantil. Campinas: Alínea, 2011.

BRASIL. Ministério da Educação. Secretaria de Educação Básica. Diretrizes Curriculares Nacionais para a Educação Infantil. Brasília, DF: MEC/SEB, 2010. Disponível em: https://web.archive.org/web/20200515110515/https://ndi.ufsc. br/files/2012/02/Diretrizes-Curriculares-para-a-E-I.pdf. Acesso em: 10 jun. 2020.

BRASIL. Base Nacional Comum Curricular. Brasília, DF: MEC/SEB, 2017. Disponível em: http://basenacionalcomum. mec.gov.br/\#/site/inicio. Acesso em: 10 jun. 2020.

CUNHA, Susana Rangel Vieira da et al. (org.). As artes do universo infantil. Porto Alegre: Mediação, 2017.

DEHEINZELIN, Monique. A fome com a vontade de comer: uma proposta curricular de educação infantil. Petrópolis: Vozes, 1994.

DELIZOICOV, Demétrio; ANGOTTI, José André; PERNAMBUCO, Marta Maria Castanho Almeida. Ensino de ciências: fundamentos e métodos. 3. ed. São Paulo: Cortez, 2002.

DELGADO, Ana Cristina Coll; MULLER, Fernanda. Em busca de metodologias investigativas com crianças e suas culturas. Cadernos de Pesquisa, São Paulo, v. 35, n. 125, p. 161-179, maio 2005. Disponível em https://www.scielo.br/ pdf/cp/v35n125/a0935125.pdf. Acesso em: 11 jun. 2020.

FREIRE, Madalena. A paixão de conhecer o mundo. Rio de Janeiro: Paz e Terra, 2007.

PERNAMBUCO, Marta Maria Castanho Almeida. Educação e escola como movimento: do ensino de ciência à transformação da escola pública. 1994. Tese (Doutorado em Ensino de Ciências) - Universidade de São Paulo, São Paulo, 1994.

RÊGO, Maria Carmem Freire Diógenes. Currículo em movimento. Caderno Faça e Conte, Natal, v. 2, ano 2, p. 61-82, 1999.

TIRIBA, Léa. Crianças, natureza e Educação Infantil. In: REUNIÃO DA ANPEd, 29., 2006, Caxambu. Anais [...]. Caxambu: GT7, 2006. Disponível em http://29reuniao.anped.org.br/trabalhos/trabalho/GT07-2304--Int.pdf. Acesso em: 13 jun. 2019.

Data de submissão: 17/06/2020

Data de aceite: $17 / 07 / 2020$ 